\title{
Review Article \\ Biological Aspects of Emerging Benzothiazoles: A Short Review
}

\author{
Ruhi Ali and Nadeem Siddiqui \\ Department of Pharmaceutical Chemistry, Faculty of Pharmacy, Jamia Hamdard, Hamdard University, New Delhi 110062, India
}

Correspondence should be addressed to Nadeem Siddiqui; nadeems_03@yahoo.co.in

Received 10 May 2013; Accepted 29 June 2013

Academic Editor: Gabriel Navarrete-Vazquez

Copyright (C) 2013 R. Ali and N. Siddiqui. This is an open access article distributed under the Creative Commons Attribution License, which permits unrestricted use, distribution, and reproduction in any medium, provided the original work is properly cited.

In recent years heterocyclic compounds analogues and derivatives have attracted wide attention due to their useful biological and pharmacological properties. Benzothiazole is among the usually occurring heterocyclic nuclei in many marine as well as natural plant products. Benzothiazole is a privileged bicyclic ring system with multiple applications. It is known to exhibit a wide range of biological properties including anticancer, antimicrobial, and antidiabetic, anticonvulsant, anti-inflammatory, antiviral, antitubercular activities. A large number of therapeutic agents are synthesized with the help of benzothiazole nucleus. During recent years there have been some interesting developments in the biological activities of benzothiazole derivatives. These compounds have special significance in the field of medicinal chemistry due to their remarkable pharmacological potentialities. This review is mainly an attempt to present the research work reported in the recent scientific literature on different biological activities of benzothiazole compounds.

\section{Introduction}

Benzothiazole is a privileged bicyclic ring system with multiple applications. In the 1950s, a number of 2aminobenzothiazoles were intensively studied as central muscle relaxants. Since then, medicinal chemists have not taken active interest in this chemical family. Biologists attention was drawn to this series when the pharmacological profile of riluzole was discovered. Riluzole (6trifluoromethoxy-2-benzothiazolamine, PK-26124, RP25279, Rilutek) was found to interfere with glutamate neurotransmission in biochemical, electrophysiological, and behavioral experiments. After that benzothiazole derivatives have been studied extensively and found to have diverse chemical reactivity and broad spectrum of biological activity.

A work by Dr. Malcolm Stevens of the Cancer Research UK Group at Nottingham University showed the potential of benzothiazole (NSC 674495) and related compounds as anticancer agents. Phortress (NSC 710305) is the lead compound from this work. This agent has demonstrated activity against breast tumors, regardless of estrogen receptor status, and against ovarian, renal, lung, and colon cancer cells (see Figure 1).
Being a heterocyclic compound, benzothiazole finds use in research as a starting material for the synthesis of larger, usually bioactive structures. Its aromaticity makes it relatively stable; although, as a heterocycle, it has reactive sites, which allow for functionalization. Benzothiazole is a colorless, slightly viscous liquid with a melting point of $2^{\circ} \mathrm{C}$ and a boiling point of $227-228^{\circ} \mathrm{C}$. The density of benzothiazole is $1.24 \mathrm{~g} / \mathrm{mL}$, and its molecular mass is $135.19 \mathrm{gmol}^{-1}$. Benzothiazole has no household use. It is used in industry and research.

A large number of therapeutic agents are synthesized with the help of benzothiazole nucleus. During recent years there have been some interesting developments in the biological activities of benzothiazole derivatives. These compounds have special significance in the field of medicinal chemistry due to their remarkable pharmacological potentialities.

\section{Biological Aspects}

Benzothiazole nucleus is found to possess a number of biological activities such as anticancer, antimicrobial, antidiabetic, anti-inflammatory, antiviral, antileishmanial, and antiviral. 


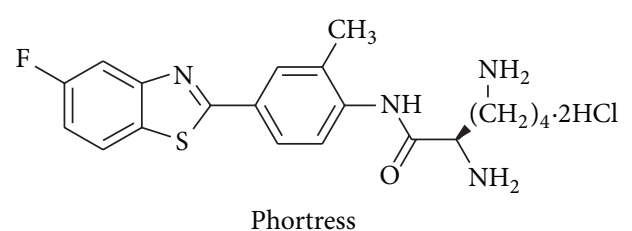

FIgURe 1

Given below is a brief account related to various biological activities of benzothiazole derivatives.

2.1. Anticancer Activity. Cancer is a serious worldwide health threat, killing almost seven million people a year, and poses great challenges to medical science. The global research efforts in this field are focused both on the development of new potent antineoplastic agents and on the discovery of novel biological targets. Novel benzothiazole-2-thiol derivatives (1) were synthesized by Wang et al. [1], and their antiproliferative activities on HepG2 and MCF-7 cells were investigated. Most compounds had inhibitory effects on cell growth, and some of them were more effective than cisplatin. Kumbhare et al. [2] synthesised benzothiazolylthiocarbamides (2) using a catalytic amount of 4dimethylaminopyridine (DMAP) followed by its chemoselective oxidative cyclization with 1,3 -di- $n$-butylimidazolium tribromide[bbim][Br3] to afford the N-bis-benzothiazole derivatives. All the synthesized compounds were evaluated for cytotoxic activity against two human monocytic cell lines (U 937, THP-1) and a mouse melanoma cell line (B16-F10). Jin et al. [3] synthesized $\gamma$-aminophosphonates (3) containing benzothiazole and fluorine moiety by Mannich-type addition in ionic liquid media with high yield and short reaction time. The newly synthesized compounds were evaluated for their anticancer activities against PC3, A431, A375, and Bcap37 cells in vitro by the MTT method. Five series of thiourea derivatives (4) bearing benzothiazole moiety were efficiently synthesized by Saeed et al. [4] and evaluated for antimicrobial and anticancer activities. Havrylyuk et al. [5] have performed antitumor screening of several novel 4-thiazolidinones with benzothiazole moiety (5). In vitro anticancer activity of the synthesized compounds was tested by the National Cancer Institute, and two of them have revealed the anticancer activity on leukemia, melanoma, lung, colon, CNS, ovarian, renal, prostate, and breast cancers cell lines. A hybrid pharmacophore approach was used to design and synthesize isatin-benzothiazole analogs (6) by Solomon et al. [6] to examine their antibreast cancer activity. The cytotoxicity of these compounds was determined using three different human breast tumor cell lines, MDAMB231, MDA-MB468, and MCF7, and two noncancer breast epithelial cell lines, 184B5 and MCF10A. A series of benzothiazole linked pyrrolobenzodiazepine conjugates (7) attached through different alkane or alkylamine spacers was prepared by Kamal et al. [7]. Their anticancer activity, DNA thermal denaturation studies, restriction endonuclease digestion assay, and flow cytometric analysis in human melanoma cell line (A375) were investigated. Prabhu et al. [8] synthesized a novel series of 2-(3-(4-oxo-2-substituted phenylthiazolidin3-yl)phenyl)benzo[d]thiazole-6-carboxylic acid derivatives PP1-PP8 (8) by various benzothiazole Schiff's bases by reaction with thioglycolic acid and evaluated their in vitro anticancer activity by 3-(4,5-dimethylthiazole-2-yl)-2,5diphenyltetrazoliumbromide (MTT) assay on human cervical cancer cell line (HeLa). Caputo et al. [9] synthesised two sets of benzothiazole derivatives bearing at C-2 an arylamide or an arylurea moiety (9) and evaluated in vitro primary anticancer assay against a panel of 60 human tumor cell lines. Chen et al. [10] have done a quantitative structureactivity relationship (QSAR) on a series of benzothiazole derivatives (10) showing a potent and selective cytotoxicity against a tumorigenic cell line by using the density functional theory (DFT), molecular mechanics $(\mathrm{MM}+)$, and statistical methods, and the QSAR equation was established via a correlation analysis and a stepwise regression analysis. A series of new 2-phenylbenzothiazoles (11) has been synthesized by Mortimer et al. [11] on the basis of the discovery of the potent and selective in vitro antitumor properties of 2-(3,4-dimethoxyphenyl)-5-fluorobenzothiazole. To identify novel small molecules to target Class I and Class II histone deacetylase (HDAC) enzymes, Oanh et al. [12] have prepared two series of benzothiazole-containing analogues of SAHA (12). It was found that several compounds with 6C-bridge linking benzothiazole moiety and hydroxamic functional groups showed good inhibition against HDAC3 and HDAC 4 at as low as $\mu \mathrm{g} / \mathrm{mL}$ and exhibited potent cytotoxicity against five cancer cell lines with average $\mathrm{IC}_{50}$ values of as low as $0.81 \mu \mathrm{g} / \mathrm{mL}$, almost equipotent to SAHA. The "one pot" condensation reaction for the synthesis of phthalic imide derivative (benzothiazole containing phthalimide) (13), exhibiting in vitro cytotoxic potential on human cancer cell lines, has been described by Kok et al. [13]. They further demonstrated that both caspase-dependent and -independent pathways are involved in our novel benzothiazole containing phthalimide induced apoptosis on cancer cells (see Figure 2).

2.2. Antimicrobial Activity. The design of new compounds to deal with resistant bacteria and fungi has become one of the most important areas of antibacterial and antifungal research today since resistance of pathogenic bacteria and fungi toward available antimicrobial drugs is rapidly becoming a major problem worldwide. Thus the discovery of novel and potent antibacterial as well as antifungal agent is more demanding and challenging for chemists and pharmacists nowadays. Sahu et al. [14] have synthesized a series of $4 \mathrm{H}$-pyrimido[2,1-b][1,3]benzothiazole derivatives (14) and evaluated their antibacterial activities against gram-positive and gram-negative bacteria, namely, Staphylococcus aureus, Pseudomonas aeruginosa, Salmonella typhi, Escherichia coli, Bacillus cereus, and Providencia rettegeri. A new class of 4-arylhydrazono-1-benzothiazolyl-3methylpyrazolin-5-ones and 4-arylazo-1-benzothiazolyl-3,5dimethylpyrazoles (15) were designed as pharmacophore hybrids between pyrazolinone/pyrazole and benzothiazole moiety by Amir et al. [15] and screened for antimicrobial activity. The synthesis of sydnone sulfonamides bearing 
<smiles>[R3]CNC(=O)CSc1nc2ccc(NC([R])=O)cc2s1</smiles>

(1)

(2)

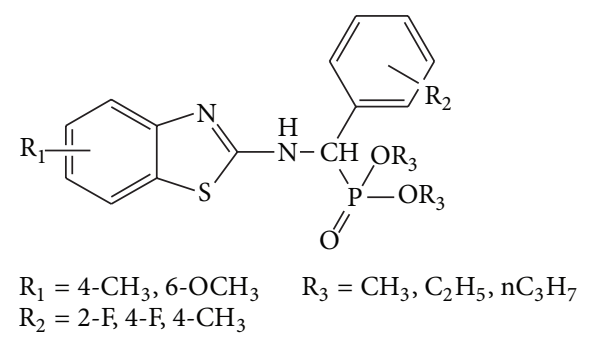

(3)<smiles>[R]C(=O)NC(=S)Nc1nc2cc([R])ccc2s1</smiles>

$\mathrm{R}=\mathrm{H}, \mathrm{Br}, \mathrm{NO}_{2}$

$\mathrm{R}_{1}=$ phenyl, $\mathrm{n}$-butyl, 4-nitrophenyl

(4)<smiles>[R]C=C1SC(=S)N(N(C(C)=O)c2nc3ccccc3s2)C1=O</smiles>

$\mathrm{R}=$ 4-chlorophenyl, 4-diethylaminophenyl

(5)<smiles>[R]N([R])C[C@@H]1C(=O)[C@@H](Nc2nc3ccc(C)cc3s2)c2ccccc21</smiles>

(6)

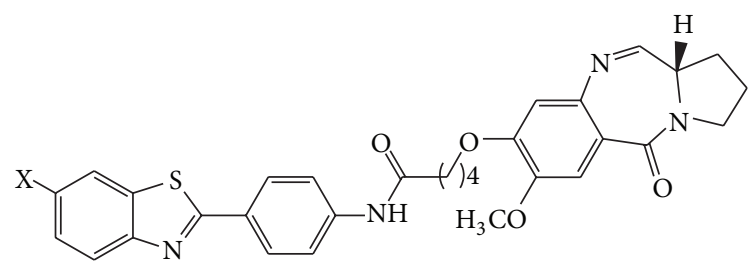

$\mathrm{X}=\mathrm{H}, \mathrm{F}$

(7)<smiles>O=C(O)c1ccc2nc(-c3cccc(N4C(=O)CSC4c4ccccc4)c3)sc2c1</smiles>

$\mathrm{R}=\mathrm{H}, \mathrm{p}-\mathrm{Cl}, \mathrm{m}-\mathrm{F}, \mathrm{p}-\mathrm{NO}_{2}, \mathrm{p}-\mathrm{OCH}_{3}$

(8)

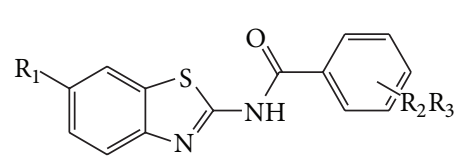

$\mathrm{R}_{1}=\mathrm{OCH}_{3}, \mathrm{OCF}_{3} \quad \mathrm{R}_{3}=\mathrm{H}, 6-\mathrm{F}$ $\mathrm{R}_{2}=4-\mathrm{F}, 2-\mathrm{F}, 4-\mathrm{OCH}_{3}$

(9)

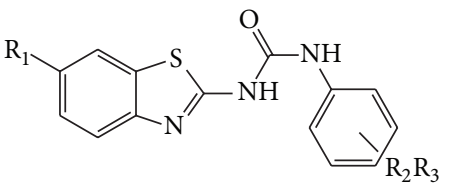<smiles>Cn1ncc([N+](=O)[O-])c1C(=O)Nc1ccc2nc(NC(=O)C3CCCCC3)sc2c1</smiles>

(10)<smiles>[R]c1cc(-c2nc3ccccc3s2)cc([R])c1[R]</smiles>

$\begin{array}{ll}\mathrm{R}=\mathrm{H}, 5-\mathrm{Cl}, 5-\mathrm{Br} & \mathrm{R}_{3}=\mathrm{OMe}, \mathrm{R}_{4}=\mathrm{H}, \mathrm{OH} \\ \mathrm{R}_{1}=\mathrm{H}, \mathrm{R}_{2}=\mathrm{OMe}, \mathrm{OEt}, & \end{array}$

(11)

FIgUre 2: Continued. 


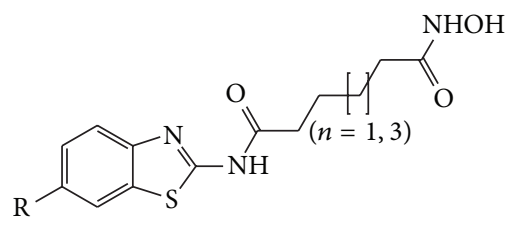

$\mathrm{R}=\mathrm{H}, \mathrm{CH}_{3}, \mathrm{OMe}, \mathrm{OEt}$

(12)

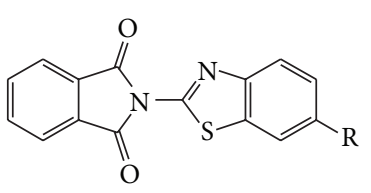

$\mathrm{R}=\mathrm{H}, \mathrm{OCF}_{3}$

Figure 2

thiazole, benzothiazole (16), and pyrimidine heterocycles is described by Asundaria and Patel [16] and evaluated for their antibacterial activity against some important Gram-positive and Gram-negative bacterial strains. A new series of 2-[4-(4substitutedbenzamido/phenylacetamido)phenyl] benzothiazole derivatives (17) were synthesized by Bolelli et al. [17] and evaluated for antibacterial and antifungal activities against Staphylococcus aureus, Bacillus subtilis, Klebsiella pneumoniae, Pseudomonas aeruginosa, and Escherichia coli with their drug-resistant isolates and a yeast Candida albicans. Sharma et al. [18] have synthesized 4-Phenyl-2H-pyrimido[2,1b]benzothiazol-2-ones (18) in quantitative yields by the reaction of 2-aminobenzothiazoles with alkynoic acid. The antimicrobial activity of the synthesized compounds was tested against bacterial species, Bacillus coagulans, Bacillus subtilis, Staphylococcus aureus, and Pseudomonas aeruginosa. $\mathrm{N}$-Myristoyltransferase has been a promising new target for the design of novel antifungal agents with new mode of action. Molecular docking and three-dimensional quantitative structure activity relationship (3D-QSAR) methods, CoMFA and CoMSIA, were applied by Sheng et al. [19] to a set of novel benzothiazole (19) Candida albicans Nmyristoyltransferase (CaNmt) inhibitors. The binding mode of the compounds at the active site of CaNmt was explored using flexible docking method, and various hydrophobic and hydrogen-bonding interactions were observed between the benzothiazole inhibitors and the target enzyme. A novel series of Schiff's bases of benzothiazole derivatives (20) were synthesized by Soni et al. [20]. All the synthesized compounds were screened for their antimicrobial activity. A novel, one-pot, simple, and efficient procedure for $4 \mathrm{H}$ pyrimido[2,1-b]benzothiazole derivatives (21) of curcumin under solvent and solvent free conditions in microwave with good yield is synthesized by Sahu et al. [21]. The synthesized compounds were evaluated for their antibacterial activity against gram-positive and gram-negative bacteria, namely, Staphylococcus aureus, Pseudomonas aeruginosa, Salmonella typhi, Escherichia coli, Bacillus cereus and Providencia rettgeri, and antifungal activity against fungi, namely, Aspergillus niger, Aspergillus fumigates, and Aspergillus flavus. Tomi et al. [22] have reported new derivatives of five-member heterocyclic compounds containing oxazole and benzothiazole rings (22). This study was designed to show the microbial activity difference for two types of five-member heterocyclic rings. The compounds were screened for antibacterial activity against Escherichia coli, Staphylococcus aureus, and Pseudomonas aeruginosa in nutrient agar medium and for antifungal activity against Aspergillus niger and Candida albicans in Sabouraud's dextrose agar medium. In an endeavor to find a new class of antimicrobial agents, a series of 2-(1,3benzothiazol-2-yl)-5-(diethylamino)phenol (23) and their derivatives were synthesized by Padalkar et al. [23] and evaluated for in vitro antibacterial activities against Escherichia coli and Staphylococcus aureus strains and in vitro antifungal activity against Candida albicans and Aspergillus niger strains by using serial dilution method. A series of novel thiazolidin4-ones and azetidin-2-ones (24) were synthesized from N-(6chlorobenzo[d]thiazol-2-yl)hydrazine carboxamide derivatives of the benzothiazole class. Antimicrobial properties of the title compound derivatives were investigated by Gilani et al. [24] against one gram-positive bacteria (Staphylococcus aureus), three gram-negative bacteria (Escherichia coli, Pseudomonas aeruginosa, Klebsiella pneumoniae), and five fungi (Candida albicans, Aspergillus niger, Aspergillus flavus, Monascus purpureus, and Penicillium citrinum) using serial plate dilution method (see Figure 3).

2.3. Anticonvulsant Activity. According to International League against Epilepsy and International Bureau of Epilepsy, an epileptic seizure is a transient occurrence of signs and symptoms due to abnormal excessive or asynchronous neuronal activity in the brain. Studies indicate that only a significant group of patients $(20-30 \%)$ are responding to currently used therapeutic agents. Thus there is still a need for new antiepileptic drugs as the clinical efficacy, tolerability, toxicity, or pharmacokinetic properties of existing AEDs may not be satisfactory. A new series of N(6-chlorobenzothiazol-2-yl)-2-substituted-acetamides (25) and $\mathrm{N}$-(6-chlorobenzothiazol-2-yl)-2-(substituted-benzylidene)hydrazinecarbothioamides (26) were synthesized by Amir et al. [25], and in vivo anticonvulsant, and acute toxicity screening of all the synthesized compounds have been performed. 3D four-point pharmacophore measurements of the compounds were also carried out to match these with established anticonvulsants agents. Kumar et al. [26] have designed and synthesized a series of 2-[2(substituted)hydrazinyl]-1,3-benzothiazole (27) and 2-(1,3benzothiazol-2-ylsulfanyl)-N-(substituted)acetohydrazide (28). The anticonvulsant activity of the titled compounds was assessed using the $6 \mathrm{~Hz}$ psychomotor seizure test. A series of substituted benzo[d]thiazol-2-yl carbamates (29, 30) were synthesized and evaluated for anticonvulsant activity by Navale et al. [27]. Two series of analogues 
<smiles>[R]c1ccccc1C1C(C(=O)OCC)=C(C)N=C2Sc3ccccc3N21</smiles>

$\mathrm{R}$ = phenyl, 4-hydroxy phenyl, 4-methoxyphenyl

(14)

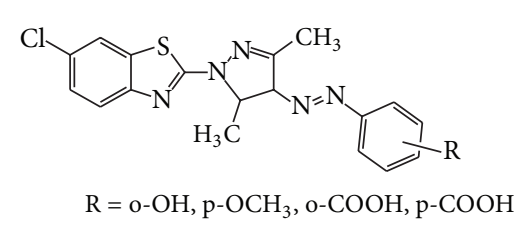

(15)

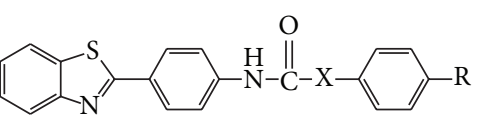

$\mathrm{X}=-\mathrm{CH}_{2}$ $\mathrm{R}=\mathrm{F}, \mathrm{Cl}, \mathrm{Br}, \mathrm{CH}_{3}, \mathrm{C}_{2} \mathrm{H}_{5}$

(17)

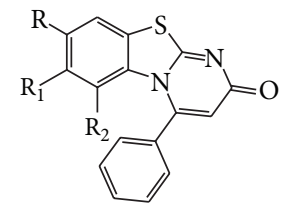<smiles>[R]CNN[X]c1ccc2nc([R])sc2c1</smiles>

$\mathrm{R}=\mathrm{H}, \mathrm{Cl}, \mathrm{NO}_{2} \quad \mathrm{R}_{2}=\mathrm{H}, \mathrm{CH}_{3}, \mathrm{Cl} \quad \mathrm{X}=\left(\mathrm{CH}_{2}\right)_{2} \mathrm{NHCO}-,\left(\mathrm{CH}_{2}\right)_{3} \mathrm{NHCO}-, \mathrm{CH}_{2} \mathrm{CONH}$ $\mathrm{R}_{1}=\mathrm{H}, \mathrm{Cl}$ $\mathrm{R}_{1}=\mathrm{NHCOC}_{6} \mathrm{H}_{11}, \mathrm{R}_{2}=\mathrm{C}_{10} \mathrm{H}_{7}$

(19)<smiles></smiles>

$\mathrm{R}=\mathrm{H}, 2-\mathrm{NO}_{2}, 3-\mathrm{NO}_{2}, 4-\mathrm{OH}$

(20)<smiles>COc1cc(/C=C/C2=NC3Sc4ccccc4N3C(c3ccccc3)=C2C(=O)CCc2ccc(O)c(OC)c2)ccc1O</smiles>

(21)

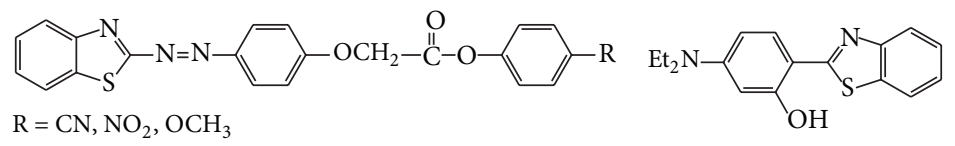

(22)

(23)<smiles>[R]c1ccccc1C1C(=O)C(Cl)C1NC(=O)Nc1nc2ccc(Cl)cc2s1</smiles>

$\mathrm{R}$ = phenyl, chlorophenyl, dichlorophenyl

(24)

Figure 3

of riluzole, a blocker of excitatory amino acid mediated neurotransmission, have been synthesized: monosubstituted 2-benzothiazolamines (31) and 3-substituted derivatives (32) by Jimonet et al. [28]. A series of 1,3-benzothiazol-2-yl benzamides (33) were prepared in satisfactory yield by Rana et al. [29] and evaluated for their anticonvulsant activity, neurotoxicity, CNS depressant effects study, and other toxicity studies. Siddiqui et al. [30] have prepared a series of 1,3-benzothiazol-2-yl-semicarbazones (34) in satisfactory yield and evaluated for their anticonvulsant, neurotoxicity and other toxicity studies. A series of 6-substituted-[3substituted-prop-2-eneamido]benzothiazole (35) and 6-substituted-2-[(1-acetyl-5-substituted)-2-pyrazolin-3yl]aminobenzothiazole (36) were synthesized by Amnerkar and Bhusari [31] using appropriate synthetic route and evaluated experimentally against maximal electroshock 
<smiles>[R]CC(=O)Nc1nc2ccc(Cl)cc2s1</smiles>

$\mathrm{R}=$ tert-butylamino, 4-chlorophenylamino, diphenylamino

(25)

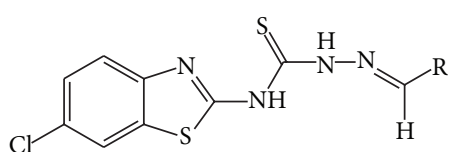

$\mathrm{R}=$ phenyl, 4-Cl phenyl, 4-F phenyl, 2-Cl phenyl

(26)

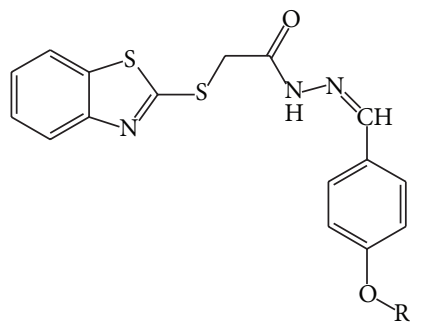

$\mathrm{R}=$ phenyl, 4-Cl phenyl, 4- $\mathrm{NO}_{2}$ phenyl

(28)

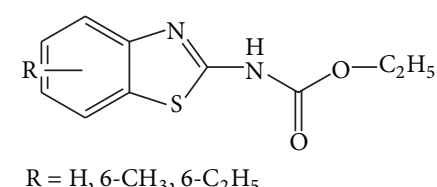

(29)

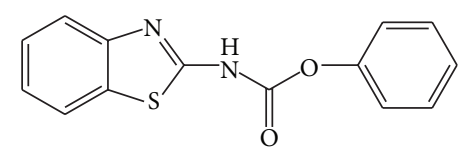

(30)<smiles>[R]n1c(=N)sc2cc(OC(F)(F)F)ccc21</smiles>

$\mathrm{R}=\mathrm{CH}_{3}, \mathrm{C}_{2} \mathrm{H}_{5}, \mathrm{C}_{3} \mathrm{H}_{7}$, allyl

(31)<smiles>[R]c1ccc2nc(N)sc2c1</smiles>

$\mathrm{R}=\mathrm{H}, \mathrm{Cl}, \mathrm{Br}, \mathrm{OCF}_{3}$

(32)

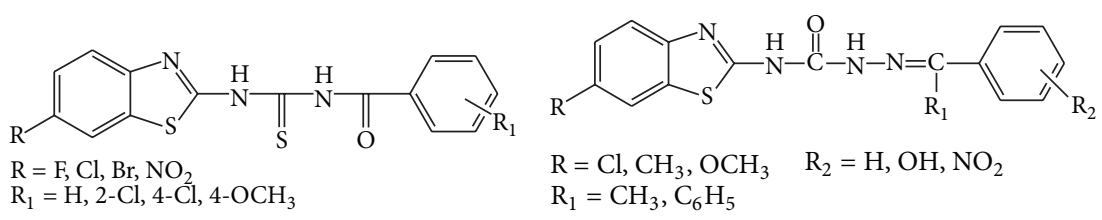

(33)

(34)

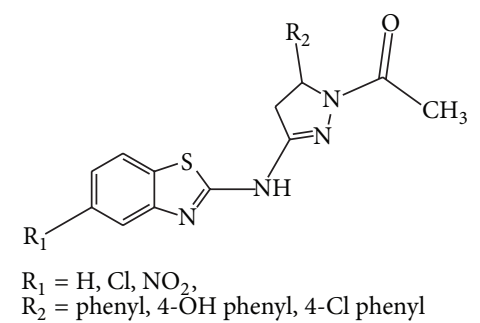

(35)<smiles>O=C(CCC(=O)c1ccccc1)Nc1nc2ccccc2s1</smiles>

$\mathrm{R}=\mathrm{H}, \mathrm{Cl}, \mathrm{Br}, \mathrm{NO}_{2}$

(36)<smiles>O=C(Cc1nc2ccccc2s1)c1ccccc1C(=O)c1ccccc1</smiles><smiles>[R]c1cc2sc(-n3cnc4ccc(Br)cc4c3=O)nc2c([R])c1[R]</smiles>

$\mathrm{R}, \mathrm{R}_{1}, \mathrm{R}_{2}=\mathrm{H}, \mathrm{Cl}, \mathrm{CH}_{3}, \mathrm{OCH}_{3}$

(38)

(a)

FIGURE 4: Continued. 


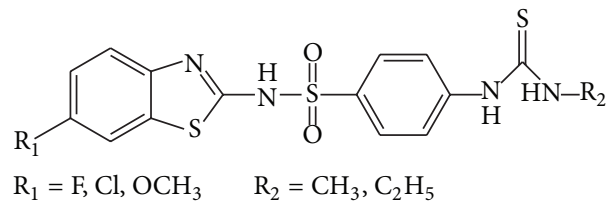

(39)

(b)

FIGURE 4<smiles>[R3]c1ccc(S(=O)(=O)Nc2nc3ccc([R1])cc3s2)cc1</smiles>

(40)

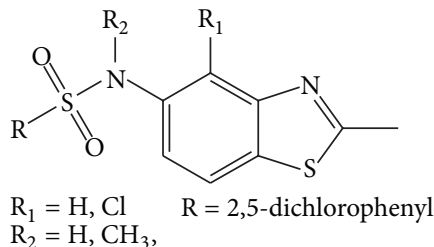

(42)<smiles>[R]C(=O)/C=C(/[SiH3])Nc1nc2cc([R1])c([R2])cc2s1</smiles>
$\mathrm{R}=\mathrm{C}_{6} \mathrm{H}_{5}, 4-\mathrm{ClC}_{6} \mathrm{H}_{5}, 4-\mathrm{BrC}_{6} \mathrm{H}_{5} \quad \mathrm{R}_{2}=\mathrm{H}, \mathrm{CH}_{3}, 6-\mathrm{OC}_{2} \mathrm{H}_{5}$ $\mathrm{R}_{1}=\mathrm{H}, 5-\mathrm{CH}_{3}$

(41)

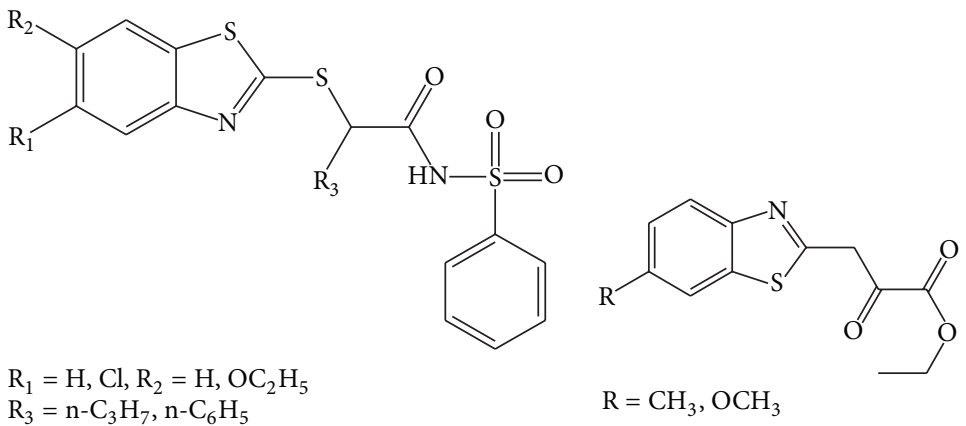

(44)

(45)

Figure 5

test. Selected compounds were evaluated for neurotoxicity, hepatotoxicity, and behavioral study.

A series of $\mathrm{N}$-(substituted benzothiazol-2-yl)amide derivatives (37) were synthesized by the EDC coupling reactions of substituted-benzothiazol-2-amine with 4-oxo4-phenylbutanoic acid-2-benzoylbenzoic acid and evaluated for their anticonvulsant and neuroprotective effect by Hassan et al. [32]. A series of 6-bromo-2-ethyl-3-(substitutedbenzo[d]thiazol-2-yl)quinazolin-4(3H)-one (38) were synthesized using appropriate synthetic route and evaluated experimentally by the Maximal Electroshock (MES) and the PTZ-induced seizure methods by Ugale et al. [33]. A series of sulfonamide derivatives (39) were synthesized in good yield by Siddiqui et al. [34] and evaluated for their possible anticonvulsant activity and neurotoxicily study (see Figure 4).

2.4. Antidiabetic Activity. Diabetes mellitus is characterized by chronic hyperglycemia and belongs to a group of metabolic disorders with multiple etiologies. Recent estimates from the year 2000 indicate that there are 171 million 


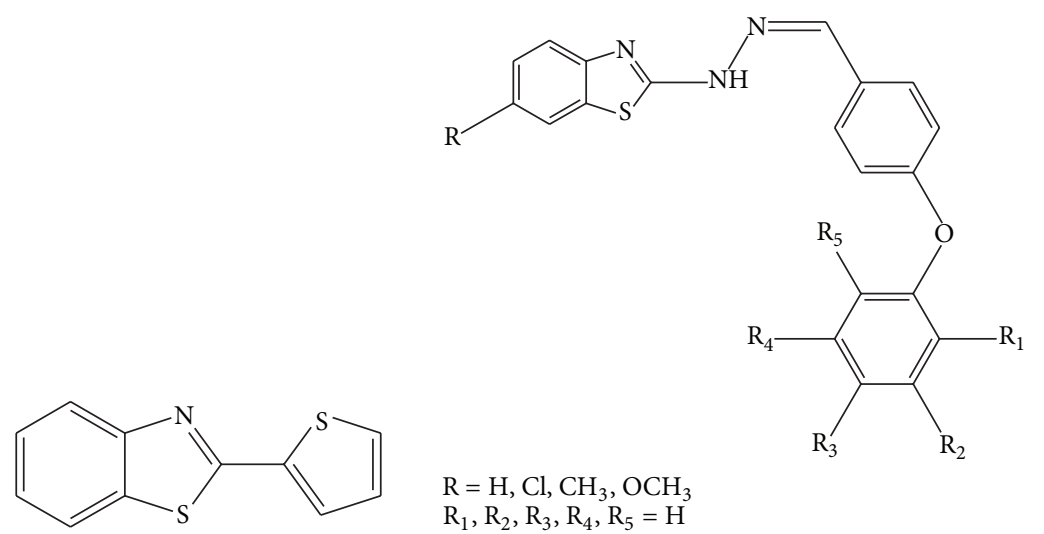

(46)

(47)<smiles>Oc1ccccc1/C=N/Nc1nc2ccccc2s1</smiles>

(48)<smiles>CCOC(=O)C(=O)Nc1nc2ccc([N+](=O)[O-])cc2s1</smiles>

(49)

Figure 6<smiles>[R]=C[SiH](C)C(=O)N[C@@H](Cc1ccccc1)CC(O)CN1CC(C)c2cc3ncsc3cc2S1(=O)=O</smiles>

(50)

FIGURE 7

people in the world with diabetes, and this is projected to increase to 366 million by 2030. There is thus a growing need for effective therapies to achieve optimal glycemic control in the management of diabetes. N-(6-substituted1,3-benzothiazol-2-yl)benzenesulfonamide derivatives (40) were synthesized and evaluated for their in vivo antidiabetic activity in a noninsulin-dependent diabetes mellitus rat model and also evaluated for 11-HSD1 and PTP-1B enzymes by Moreno-Díaz et al. [35]. A novel series of substituted (E)3-(Benzo[d]thiazol-2-ylamino)phenylprop-2-en-1-ones (41) were synthesized and were evaluated for their antidiabetic activity by Patil et al. [36]. Selective inhibitors of 11betahydroxysteroid dehydrogenase type 1 (11 $\beta$-HSD1) have considerable potential as treatments for metabolic diseases, such as diabetes mellitus type 2 or obesity. Su et al. [37] reported the discovery and synthesis of a series of novel benzothiazole derivatives (42) and their inhibitory activities against 11HSD1 from human hepatic microsomes measured using a radioimmunoassay (RIA) method. Benzothiazole derivatives of thiazolidinones (43) were synthesized by Jeon et al. [38] and assayed for activity on PPAR subtypes and inhibitory activity of NO production in lipopolysaccharide activated macrophages. Most of the compounds were identified as $\operatorname{PPAR} \gamma$ agonist, indicating their potential as drug candidate for diabetes. A group of phenylsulfonamides (44) were synthesized by Ammazzalorso et al. [39] and evaluated in vitro against the agonistic effect of GW7647; they showed an inhibitory effect on PPARa activation, with best compounds revealing a dose-dependent antagonistic profile.

Navarrete-Vazquez et al. [40] prepared ethyl 2-(6-substituted benzo[ $d]$ thiazol-2-ylamino)-2-oxoacetate derivatives (45) using a one-step reaction. The in vitro inhibitory activity 
<smiles>[R][R]Oc1cccc(-n2cc(CSc3nc4ccccc4s3)nn2)c1</smiles>

(51)

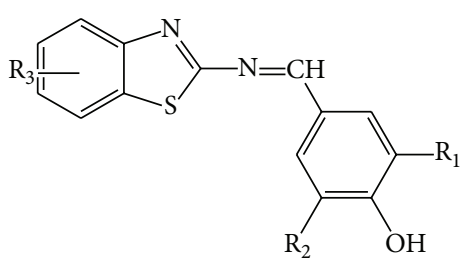

$\mathrm{R}_{1}, \mathrm{R}_{2}=\mathrm{H}, \mathrm{OH}, \mathrm{Cl}$ $\mathrm{R}_{3}=\mathrm{F}, \mathrm{Cl}, \mathrm{Br}$

(52)

Figure 8<smiles>Nc1c(-c2nc3ccccc3s2)ccc2[nH]c3ccccc3c(=O)c12</smiles>

(53)

Figure 9

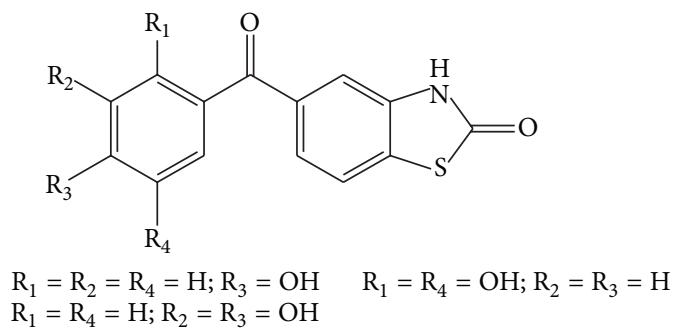

(54)<smiles>N=c1sc2ccccc2n1CCSS(=O)(=O)O</smiles>

(55)

FIGURE 10

of the compounds against protein tyrosine phosphatase- $1 \mathrm{~B}$ (PTP-1B) was evaluated. The compounds were evaluated for their in vivo hypoglycemic activity, showing significant lowering of plasma glucose concentration in acute normoglycemic model and oral glucose tolerance test similar to the effect exerted for hypoglycemic drug glibenclamide. (see Figure 5)

2.5. Antitubercular Activity. Synthesis, characterization, DFT simulation, and biological assays of two new metal complexes of 2-(2-thienyl)benzothiazole-BTT (46) are reported by Pereira et al. [41]. Both complexes showed a good activity against Mycobacterium tuberulosis. A series of structurally novel, substituted 2-(2-(4-aryloxybenzylidene)hydrazinyl)benzothiazole derivatives incorporating 2-hydrazinobenzothiazole and 4-(aryloxy)benzaldehyde (47) were designed and synthesized using molecular hybridization approach by Telvekar et al. [42]. All the synthesized compounds exhibited promising activity (MIC $1.5-29.00 \mu \mathrm{g} / \mathrm{mL}$ ) against Mycobacterium tuberculosis H37Rv strains using REMA. Derivatives of 2-hydrazinobenzothiazole (48) have been synthesized for testing as antituberculous agents by Katz [43]. HisG is an ATPphosphoribosyl transferase (ATPPRTase) that catalyzes the first step in the biosynthetic pathway for histidine. Among the enzymes in this pathway, only HisG represents a potential drug target for tuberculosis. To discover more potent and diverse inhibitors, virtual screening was performed by Cho et al. [44], and several of the hits contained a nitrobenzothiazole fragment (49), which was predicted to dock into the monophosphate-binding loop, and this binding mode was confirmed by crystallographic evidence (see Figure 6).

2.6. Antiviral Activity. Nagarajan et al. [45] showed that the replacement of $t$-butylurea moiety by benzothiazole sulfonamide (50) provided protease inhibitors with improved potency and antiviral activity since the inhibitors incorporated a variety of isosteres including the hydroxyethylurea at the protease cleavage site. Some of the compounds had shown good oral bioavailability and half-life in rats. The synthesis of benzothiazole derivatives led them to explore other heterocyclic compounds. During the course of their studies, 
they also developed an efficient synthesis of benzothiazole-6sulfonic acid via a two-step procedure starting from sulfanilamide (see Figure 7).

2.7. Anti-Inflammatory Activity. A focused library of novel bis-heterocycles encompassing 2-mercaptobenzothiazole (51) were synthesized using click chemistry approach by Shafi et al. [46]. The synthesized compounds have been tested for their anti-inflammatory activity by using biochemical cyclooxygenase (COX) activity assays and carrageenaninduced hind paw edema. Geronikaki et al. [47] synthesized several new thiazolyl/thiazolinyl/benzothiazolyl Schiff bases (52). The referred compounds were reported to act as lipoxygenase inhibitors affecting inflammation and/or psoriasis (see Figure 8).

2.8. Antileishmanial Activity. (1,3-Benzothiazol-2-yl)amino9-(10H)-acridinone derivatives (53) were synthesized by Delmas et al. [48] via a procedure based on the Ullman reaction and were assessed for their in vitro antileishmanial activity (see Figure 9).

2.9. Antioxidant Activity. Tzanova et al. [49] described an efficient synthesis of three novel benzophenones containing 1,3-thiazol moiety (54). Their antioxidant power was evaluated in vitro and in three cell lines (the cancerous MCF7, and the noncancerous hTERT-HME1 mammary cells, and the H9c2 cardiomyoblastic cells). One analogue 5-(2,5-dihydroxybenzoyl)-2(3H)-benzothiazolone displayed an important antioxidant activity and low cytotoxicity and could decrease reactive oxygen species production generated by tert-butyl hydroperoxide ( $t \mathrm{BHP})$ in all three cell lines. Cressier et al. [50] reported the synthesis and characterization of new compounds derived from benzothiazoles and thiadiazoles (55). The radioprotective activity had also been evaluated in mice. Some of these compounds could be good radioprotectors (see Figure 10).

\section{Conclusion}

The present review highlights the use of benzothiazole moiety as a template for development of newer therapeutic agents. Biological properties of the nucleus include anticancer, antidiabetic, analgesic, anti-inflammatory, and antimicrobial. With proper designing and structure-activity relationship studies of known benzothiazole, prospective compounds can be designed and synthesized for a variety of biological activities.

\section{Acknowledgment}

The authors wish to express their gratitude to UGC, New Delhi, India, for the financial aid.

\section{References}

[1] Z. Wang, X. Shi, J. Wang et al., "Synthesis, structure-activity relationships and preliminary antitumor evaluation of benzothiazole-2-thiol derivatives as novel apoptosis inducers," Bioorganic and Medicinal Chemistry Letters, vol. 21, no. 4, pp. 1097-1101, 2011.

[2] R. M. Kumbhare, T. Dadmal, U. Kosurkar, V. Sridhar, and J. V. Rao, "Synthesis and cytotoxic evaluation of thiourea and $\mathrm{N}$ bis-benzothiazole derivatives: a novel class of cytotoxic agents," Bioorganic and Medicinal Chemistry Letters, vol. 22, no. 1, pp. 453-455, 2012.

[3] L. Jin, B. Song, G. Zhang et al., "Synthesis, X-ray crystallographic analysis, and antitumor activity of $N$-(benzothiazole2-yl)-1-(fluorophenyl)-O,O-dialkyl- $\alpha$-aminophosphonates," Bioorganic and Medicinal Chemistry Letters, vol. 16, no. 6, pp. 1537-1543, 2006.

[4] S. Saeed, N. Rashid, P. G. Jones, M. Ali, and R. Hussain, "Synthesis, characterization and biological evaluation of some thiourea derivatives bearing benzothiazole moiety as potential antimicrobial and anticancer agents," European Journal of Medicinal Chemistry, vol. 45, no. 4, pp. 1323-1331, 2010.

[5] D. Havrylyuk, L. Mosula, B. Zimenkovsky, O. Vasylenko, A. Gzella, and R. Lesyk, "Synthesis and anticancer activity evaluation of 4-thiazolidinones containing benzothiazole moiety," European Journal of Medicinal Chemistry, vol. 45, no. 11, pp. 5012-5021, 2010.

[6] V. R. Solomon, C. Hu, and H. Lee, "Hybrid pharmacophore design and synthesis of isatin-benzothiazole analogs for their anti-breast cancer activity," Bioorganic and Medicinal Chemistry Letters, vol. 17, no. 21, pp. 7585-7592, 2009.

[7] A. Kamal, K. S. Reddy, M. N. Khan et al., "Synthesis, DNAbinding ability and anticancer activity of benzothiazole/benzoxazole-pyrrolo[2,1-c] [1,4] benzodiazepine conjugates," Bioorganic and Medicinal Chemistry, vol. 18, no. 13, pp. 4747-4761, 2010.

[8] P. Prabhu, T. Panneerselvam, C. S. Shastry, A. Sivakumar, and S. Pande, "Synthesis and anticancer evaluation of 2-phenyl thiaolidinone substituted 2-phenyl benzothiazole-6-carboxylic acid derivatives," Journal of Saudi Chemical Society, 2012.

[9] R. Caputo, M. L. Calabro, N. Micale et al., "Synthesis of benzothiazole derivatives and their biological evaluation as anticancer agents," Medicinal Chemistry Research, vol. 21, pp. 2644-2651, 2012.

[10] J. Chen, L. Qian, Y. Shen, L. Chen, and K. Zheng, "A QSAR study and molecular design of benzothiazole derivatives as potent anticancer agents," Science in China B, vol. 51, no. 2, pp. 111-119, 2008.

[11] C. G. Mortimer, G. Wells, J. Crochard et al., "Antitumor benzothiazoles. 26.1 2-(3,4-dimethoxyphenyl)-5- fluorobenzothiazole (GW 610, NSC 721648), a simple fluorinated 2-arylbenzothiazole, shows potent and selective inhibitory activity against lung, colon, and breast cancer cell lines," Journal of Medicinal Chemistry, vol. 49, no. 1, pp. 179-185, 2006.

[12] D. T. Oanh, H. V. Hai, S. Park et al., "Benzothiazole-containing hydroxamic acids as histone deacetylase inhibitors and antitumor agents," Bioorganic and Medicinal Chemistry Letters, vol. 21, no. 24, pp. 7509-7512, 2011.

[13] S. H. L. Kok, R. Gambari, CH. H. Chui et al., "Synthesis and anti-cancer activity of benzothiazole containing phthalimide on human carcinoma cell lines," Bioorganic and Medicinal Chemistry, vol. 16, no. 7, pp. 3626-3631, 2008.

[14] P. K. Sahu, P. K. Sahu, J. Lal, D. Thavaselvam, and D. Agarwal, "A facile green synthesis and in vitro antimicrobial activity $4 \mathrm{H}$ pyrimido[2,1-b] [1,3] benzothiazole derivatives using aluminum 
trichloride under solvent free conditions," Medicinal Chemistry Research, vol. 21, no. 11, pp. 3826-3834, 2012.

[15] M. Amir, S. A. Javed, and M. Zaheen Hassan, "Synthesis and antimicrobial activity of pyrazolinones and pyrazoles having benzothiazole moiety," Medicinal Chemistry Research, vol. 21, no. 7, pp. 1261-1270, 2012.

[16] S. T. Asundaria and K. C. Patel, "Synthesis, characterization and antimicrobial activity of thiazole, benzothiazole and pyrimidine derivatives bearing sydnone moieties," Pharmaceutical Chemistry Journal, vol. 45, no. 12, pp. 725-731, 2012.

[17] K. Bolelli, I. Yalcin, T. Ertan-Bolelli et al., "Synthesis of novel 2-[4-(4-substitutedbenzamido/phenylacetamido)phenyl]benzothiazoles as antimicrobial agents," Medicinal Chemistry Research, vol. 21, no. 11, pp. 3818-3825, 2012.

[18] P. K. Sharma, M. Kumar, and V. Mohan, "Synthesis and antimicrobial activity of 2H-pyrimido[2,1-b]benzothiazol-2- ones," Research on Chemical Intermediates, vol. 36, no. 8, pp. 985-993, 2010.

[19] C. Sheng, J. Zhu, W. Zhang et al., “3D-QSAR and molecular docking studies on benzothiazole derivatives as Candida albicans $N$-myristoyltransferase inhibitors," European Journal of Medicinal Chemistry, vol. 42, no. 4, pp. 477-486, 2007.

[20] B. S. Soni, M. Ranawat, R. Sharma, A. Bhandari, and S. Sharma, "Synthesis and evaluation of some new benzothiazole derivatives as potential antimicrobial agents," European Journal of Medicinal Chemistry, vol. 45, no. 7, pp. 2938-2942, 2010.

[21] P. K. Sahu, P. K. Sahu, S. K. Gupta, D. Thavaselvam, and D. D. Agarwal, "Synthesis and evaluation of antimicrobial activity of $4 \mathrm{H}$-pyrimido [2,1-b] benzothiazole, pyrazole and benzylidene derivatives of curcumin," European Journal of Medicinal Chemistry, vol. 54, pp. 366-378, 2012.

[22] I. H. R. Tomi, J. H. Tomma, A. Daraji, and A. Al-Dujaili, "Synthesis, characterization and comparative study the microbial activity of some heterocyclic compounds containing oxazole and benzothiazole moieties," Journal of Saudi Chemical Society, 2012.

[23] V. S. Padalkar, B. N. Borse, V. D. Gupta et al., "Synthesis and antimicrobial activity of novel 2-substituted benzimidazole, benzoxazole and benzothiazole derivatives," Arabian Journal of Chemistry, 2012.

[24] S. Gilani, K. Nagarajan, S. P. Dixit, M. Taleuzzaman, and S. A. Khan, "Benzothiazole incorporated thiazolidin-4-ones and azetidin-2-ones derivatives: synthesis and in vitro antimicrobial evaluation," Arabian Journal of Medicinal Chemistry, 2012.

[25] M. Amir, S. Asif, I. Ali, and M. Z. Hassan, "Synthesis of benzothiazole derivatives having acetamido and carbothioamido pharmacophore as anticonvulsant agents," Medicinal Chemistry Research, vol. 21, no. 9, pp. 2661-2670, 2012.

[26] P. Kumar, B. Shrivastava, S. N. Pandeya, L. Tripathi, and J. P. Stables, "Design, synthesis, and anticonvulsant evaluation of some novel 1, 3 benzothiazol-2-yl hydrazones/acetohydrazones," Medicinal Chemistry Research, vol. 21, no. 9, pp. 2428-2442, 2012.

[27] A. Navale, S. Pawar, M. Deodhar, and A. Kale, "Synthesis of substituted benzo[d]thiazol-2-ylcarbamates as potential anticonvulsants," Medicinal Chemistry Research, vol. 22, no. 9, pp. 4316-4321, 2013.

[28] P. Jimonet, F. Audiau, M. Barreau et al., "Riluzole series. Synthesis and in vivo "antiglutamate" activity of 6- substituted-2-benzothiazolamines and 3-substituted-2-imino-benzothiazolines," Journal of Medicinal Chemistry, vol. 42, no. 15, pp. 2828-2843, 1999.
[29] A. Rana, N. Siddiqui, S. A. Khan, S. E. Haque, and M. A. Bhat, " $N$-[(6-Substituted-1,3-benzothiazole-2-yl)amino]carbonothioyl-2/4-substituted benzamides: synthesis and pharmacological evaluation," European Journal of Medicinal Chemistry, vol. 43, no. 5, pp. 1114-1122, 2008.

[30] N. Siddiqui, A. Rana, S. A. Khan, S. E. Haque, and M. A. Bhat, "Synthesis of benzothiazole semicarbazones as novel anticonvulsants-the role of hydrophobic domain," Bioorganic and Medicinal Chemistry Letters, vol. 17, no. 15, pp. 4178-4182, 2007.

[31] N. D. Amnerkar and K. P. Bhusari, "Synthesis, anticonvulsant activity and 3D-QSAR study of some prop-2-eneamido and 1acetyl-pyrazolin derivatives of aminobenzothiazole," European Journal of Medicinal Chemistry, vol. 45, no. 1, pp. 149-159, 2010.

[32] M. Z. Hassan, S. A. Khan, and M. Amir, "Design, synthesis and evaluation of $N$-(substituted benzothiazol-2-yl)amides as anticonvulsant and neuroprotective," European Journal of Medicinal Chemistry, vol. 58, pp. 206-213, 2012.

[33] V. G. Ugale, H. M. Patel, S. G. Wadodkar, S. B. Bari, A. A. Shirkhedkar, and S. J. Surana, "Quinazolino-benzothiazoles: fused pharmacophores as anticonvulsant agents," European Journal of Medicinal Chemistry, vol. 53, pp. 107-113, 2012.

[34] N. Siddiqui, S. N. Pandeya, S. A. Khan et al., "Synthesis and anticonvulsant activity of sulfonamide derivatives-hydrophobic domain," Bioorganic and Medicinal Chemistry Letters, vol. 17, no. 1, pp. 255-259, 2007.

[35] H. Moreno-Díaz, R. Villalobos-Molina, R. Ortiz-Andrade et al., "Antidiabetic activity of $N$-(6-substituted-1,3-benzothiazol-2yl)benzenesulfonamides," Bioorganic and Medicinal Chemistry Letters, vol. 18, no. 9, pp. 2871-2877, 2008.

[36] V. S. Patil, K. P. Nandre, S. Ghosh et al., "Synthesis, crystal structure and antidiabetic activity of substituted (E)-3-(Benzo [d] thiazol-2-ylamino) phenylprop-2-en-1-one," European Journal of Medicinal Chemistry, vol. 59, pp. 304-309, 2013.

[37] X. Su, N. Vicker, D. Ganeshapillai et al., "Benzothiazole derivatives as novel inhibitors of human $11 \beta$ - hydroxysteroid dehydrogenase type 1," Molecular and Cellular Endocrinology, vol. 248, no. 1-2, pp. 214-217, 2006.

[38] R. Jeon, Y. Kim, Y. Cheon, and J. Ryu, "Synthesis and biological activity of [[(heterocycloamino)alkoxy]benzyl]-2, 4thiazolidinediones as PPAR $\gamma$ agonists," Archives of Pharmacal Research, vol. 29, no. 5, pp. 394-399, 2006.

[39] A. Ammazzalorso, A. Giancristofaro, A. D’Angelo et al., "Benzothiazole-based $N$-(phenylsulfonyl)amides as a novel family of PPAR $\alpha$ antagonists," Bioorganic and Medicinal Chemistry Letters, vol. 21, no. 16, pp. 4869-4872, 2011.

[40] G. Navarrete-Vazquez, M. Ramírez-Martínez, S. Estrada-Soto et al., "Synthesis, in vitro and in silico screening of ethyl 2-(6-substituted benzo[d]thiazol-2-ylamino)-2-oxoacetates as protein-tyrosine phosphatase 1B inhibitors," European Journal of Medicinal Chemistry, vol. 53, pp. 346-355, 2012.

[41] G. A. Pereira, A. C. Massabni, E. E. Castellano et al., "A broad study of two new promising antimycobacterial drugs: $\mathrm{Ag}(\mathrm{I})$ and $\mathrm{Au}(\mathrm{I})$ complexes with 2-(2-thienyl)benzothiazole," Polyhedron, vol. 38, no. 1, pp. 291-296, 2012.

[42] V. N. Telvekar, V. K. Bairwa, K. Satardekar, and A. Bellubi, "Novel 2-(2-(4-aryloxybenzylidene) hydrazinyl)benzothiazole derivatives as anti-tubercular agents," Bioorganic and Medicinal Chemistry Letters, vol. 22, no. 1, pp. 649-652, 2012.

[43] L. Katz, "Antituberculous compounds. III. Benzothiazole and benzoxazole derivatives," Journal of the American Chemical Society, vol. 75, no. 3, pp. 712-714, 1953. 
[44] Y. Cho, T. R. Ioerger, and J. C. Sacchettini, "Discovery of novel nitrobenzothiazole inhibitors for Mycobacterium tuberculosis ATP phosphoribosyl transferase (HisG) through virtual screening," Journal of Medicinal Chemistry, vol. 51, no. 19, pp. 59845992, 2008.

[45] S. R. Nagarajan, G. A. De Crescenzo, D. P. Getman et al., "Discovery of novel benzothiazolesulfonamides as potent inhibitors of HIV-1 protease," Bioorganic and Medicinal Chemistry, vol. 11, no. 22, pp. 4769-4777, 2003.

[46] S. Shafi, M. M. Alam, N. Mulakayala et al., "Synthesis of novel 2-mercapto benzothiazole and 1,2,3-triazole based bisheterocycles: their anti-inflammatory and anti-nociceptive activities," European Journal of Medicinal Chemistry, vol. 49, pp. 324-333, 2012.

[47] A. Geronikaki, D. Hadjipavlou-Litina, and M. Amourgianou, "Novel thiazolyl, thiazolinyl and benzothiazolyl Schiff bases as possible lipoxygenase's inhibitors and anti-inflammatory agents," Farmaco, vol. 58, no. 7, pp. 489-495, 2003.

[48] F. Delmas, A. Avellaneda, C. D. Giorgio et al., "Synthesis and antileishmanial activity of (1,3-benzothiazol-2-yl) amino9-(10H)-acridinone derivatives," European Journal of Medicinal Chemistry, vol. 39, no. 8, pp. 685-690, 2004.

[49] T. Tzanova, M. Gerova, O. Petrov, M. Karaivanova, and D. Bagrel, "Synthesis and antioxidant potential of novel synthetic benzophenone analogues," European Journal of Medicinal Chemistry, vol. 44, no. 6, pp. 2724-2730, 2009.

[50] D. Cressier, C. Prouillac, P. Hernandez et al., "Synthesis, antioxidant properties and radioprotective effects of new benzothiazoles and thiadiazoles," Bioorganic and Medicinal Chemistry, vol. 17, no. 14, pp. 5275-5284, 2009. 

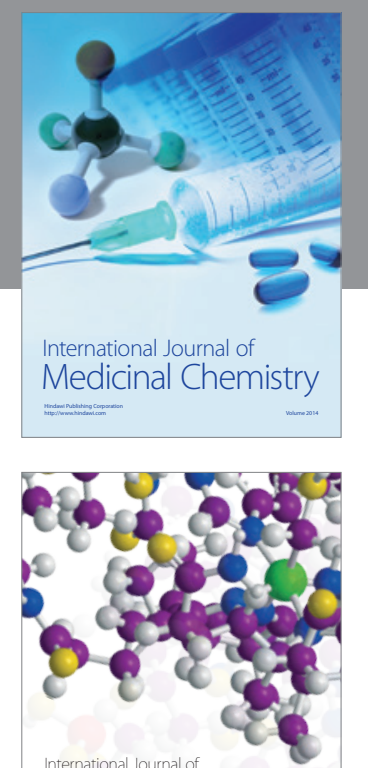

\section{Carbohydrate} Chemistry

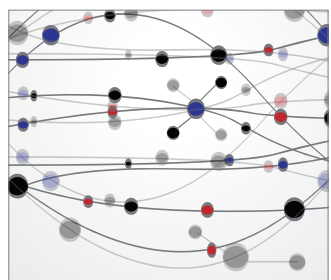

The Scientific World Journal
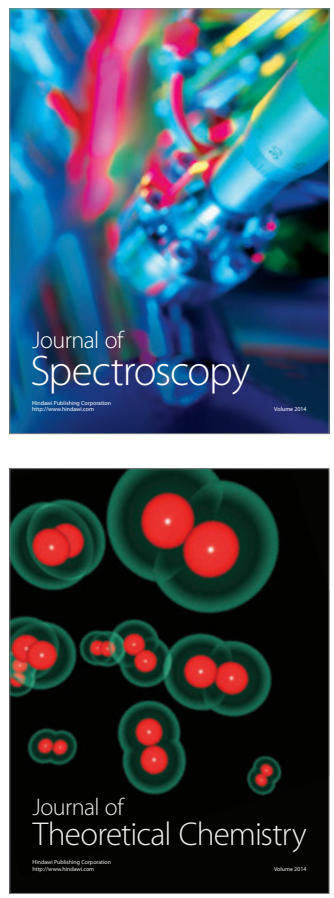
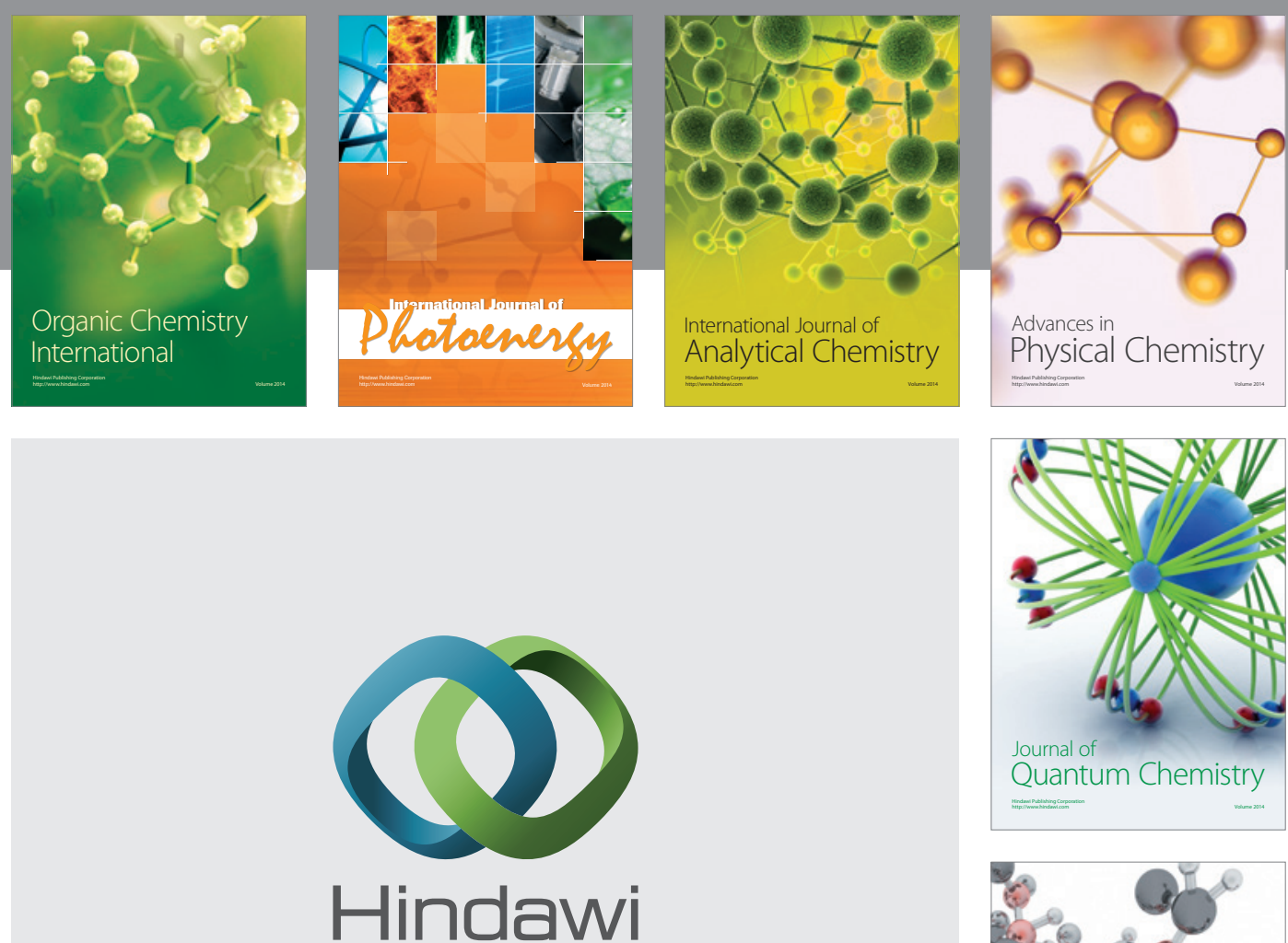

Submit your manuscripts at

http://www.hindawi.com

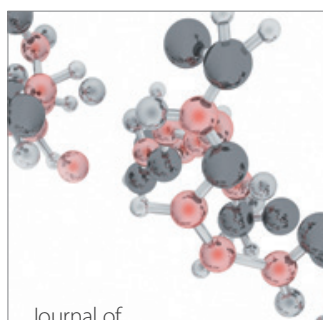

Analytical Methods

in Chemistry

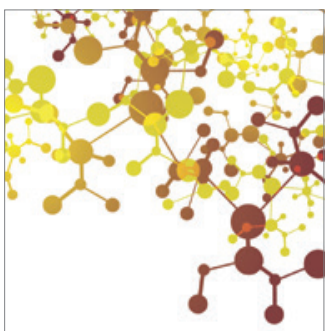

Journal of

Applied Chemistry

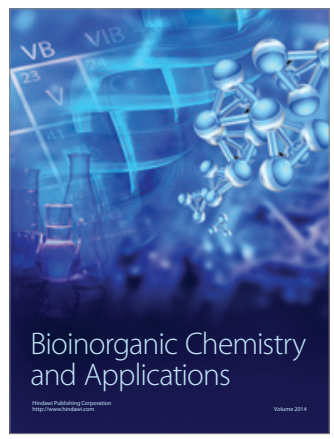

Inorganic Chemistry
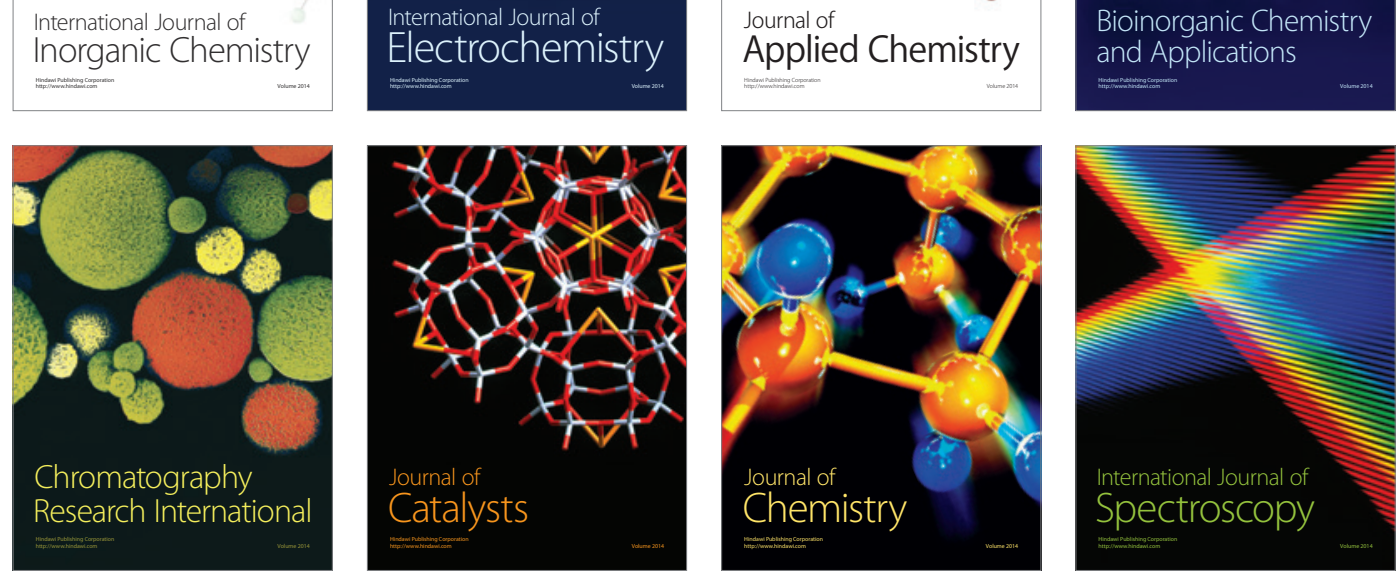